\title{
Family Caregivers' Experiences of Stroke Recovery Among Older Adults Living in Iran: A Qualitative Study
}

\author{
Ali Hesamzadeh ${ }^{1}$, Asghar Dalvandi ${ }^{1,{ }^{*}}$, Sadat Bagher Maddah ${ }^{1}$, Masoud Fallahi Khoshknab ${ }^{1}$ and \\ Fazlollah Ahmadi ${ }^{2}$ \\ ${ }^{1}$ Department of Nursing, University of Social Welfare and Rehabilitation Sciences, Tehran, IR Iran \\ ${ }^{2}$ Department of Nursing, Faculty of Medical Sciences, Tarbiat Modares University, Tehran, IR Iran \\ "Corresponding author: Department of Nursing, University of Social Welfare and Rehabilitation Sciences, Daneshjo Ave., Koodakyar St., Tehran, IR Iran. Tel: +98-2122180036, \\ Fax: +98-2122180126, E-mail: asghar.dalvandi@gmail.com
}

Received 2015 February 04; Revised 2015 March 17; Accepted 2015 April 06.

\begin{abstract}
Background: Stroke can be seen as a family matter, and nearly all stroke patients live with their families in their communities. Comprehensive insights into stroke recovery from family caregivers' point of view are lacking.

Objectives: The aim of the present study is to explore and describe family caregivers' experiences about the contributing elements of promoting the stroke recovery of older adults in the Iranian context.

Methods: A qualitative content analysis approach was conducted. From September 2013 to April 2014, 17 family caregivers from multiple physiotherapy clinics in Sari, Iran, participated in this study. Data were generated through in-depth interviews, and the content analysis method was used to determine themes.

Results: The results of data analysis were categorized into three main themes: 1) promoting functional recovery; 2) improving psychological health; and 3) strengthening social roles. The general, overarching theme was promoting positive recovery.

Conclusions: The family positively figures in the stroke patient's recovery. Health practitioners must help the stroke families effectively play their critical roles in helping their stroke patients recover.
\end{abstract}

Keywords: Stroke Recovery, Elderly, Caregiver's Experience, Cerebrovascular Accident

\section{Background}

The world health organization (WHO) estimates that 15 million people suffer strokes each year, and 5 million are left permanently disabled (1). In Iran, according to one study, the annual incidence of stroke is 139 per 100,000 people (2). The effects from stroke are a heavy burden for patients, their family caregivers, and the community as a whole. It is the third leading cause of death worldwide (3). Studies revealed that $12 \%-18 \%$ of stroke patients are dysphasic, $22 \%$ may be unable to walk, 32\% are clinically depressed, and $24 \%$ - 53\% remain dependent on family caregivers for activities of daily living (ADL) (4). Recovery has become an international concern initiated by the confluence of the health service consumer movement and a new body of research findings. The focus of the health service consumer movement continues to be on recovery primarily as a civil rights issue (5). The definition of recovery differs among different disciplines. It typically means an act of returning to a normal state, regaining possession of ex- tracting an energy source or chemical for use (6). Stroke patients need additional support from family or friends to live independently (7). A family caregiver is a person who lives daily with the patient providing assistance with hygiene care, giving comfort, feeding, encouraging rehabilitation activities, and interacting with the therapeutic team (8). Family caregivers play a key role in the recovery of stroke survivors (9). However, there has been relatively little theoretical work examining the process of recovery from family the caregivers' point of view (10). There is no single universal agreement on the conceptualization of recovery, and exploring recovery empirically has been an ongoing challenge for researchers (11). This may result in many difficulties and long-term problems for stroke patients and their family members who are usually the main caregivers within the Iranian social and cultural context (12). Evidently, there is little information available on the details of the factors promoting recovery after stroke that is given from the family caregivers' perspective. 


\section{Objectives}

The aim of this qualitative study is to explore and describe family caregivers' experiences on aspects of promoting the stroke recovery of older adults in the Iranian context.

\section{Methods}

\subsection{Study Design}

The content analysis method was deemed suitable for the present qualitative study, as it has been proven to be an effective way of providing evidence for a phenomenon (13). This method provides a clear insight about the concepts related to qualitative analysis (14).

\subsection{Setting and Participants}

The study participants consisted of 17 stroke patients' family caregivers who voluntarily participated in the study. All the participants were recruited by purposive sampling from various sites, based on the maximum variation approach, so that a wide range of caregivers was included according to the length of caregiving, relationship to the patient, gender, occupation, and marital status. The research was conducted from September 2013 to April 2014. The research sites included one physiotherapy(PT) clinic of a government referral hospital affiliated with Mazandaran University of Medical Sciences in Behshar city, Iran, three private PT clinics, and one private elderly day care center in Sari city, Iran. The inclusion criteria for participating in the study were the following: (a) caring for a stroke patient older than 60 years of age; (b) living with the patient; or (c) having a major involvement in the patient's caregiving tasks after hospital discharge. The one exclusion criterion for the caregivers was having executed the caregiving tasks for less than one month. At each initial communication, the family caregivers were informed of the nature and aim of the study and its possible risks and benefits. After obtaining their verbal consent for participation, a time and place for a personal interview were arranged. Two participants were interviewed in their homes and the remaining interviews were done in a private room in the PT clinic's office. The recruited family caregivers were assured that they could withdraw from the study at any time and their confidentiality would be preserved.

\subsection{Data Collection}

After approval from Mazandaran University of Medical Sciences was obtained, the investigators gained access to the potential participants. All the private clinic and elderly day care center managers' permissions were also obtained before entering the field. At the beginning of each semistructured interview, the researcher asked simple questions to obtain each participant's demographic data and establish the atmosphere for the following questions. The researchers had developed an interview guide which included questions such as these: Do you want to tell me what problems you have had since your patient's stroke? and How did you deal with your problems? According to the participant's response, follow-up questions were posed to explore the caregiver's experience with recovery aspects during an in-depth interview. Most interviews lasted from 35 to 110 minutes and were audiotaped for later transcription. Family caregiver interviewing continued until gaining data saturation, which means no new themes emerged during questioning.

\subsection{Data Analysis}

The conventional content analysis approach was used to analyze the data. The framework process, which involves five distinct, though interconnected stages, was applied as a hallmark in the present study (14). Accordingly, in the first, or familiarization stage, the audiotaped recordings were transcribed verbatim. Data analysis commenced after the data were obtained from the initial interviews by the team of the researchers. Each transcribed interview was read to acquire a solid overview of the whole body of information. During the second, or identifying, stage, a thematic framework identifying the key issues, concepts, and themes was developed. The data were analyzed line by line and word by word to establish the code units. The condensed meaning units were abstracted and labeled with a code, which constituted the manifest content. In the third, or index, stage, various codes were compared based on differences and similarities and then sorted into related categories and subcategories. Subsequently, relevant codes were collected into data extracts within the identified categories. The fourth, or charting, stage consisted of applying the thematic framework to the individual transcripts and building a picture of the data. The researchers read all of the collected extracts for each category and determined whether they formed a coherent pattern. The validity of each category was considered in relation to the dataset and whether the selected categories accurately reflected the meaning evident in the dataset as a whole. Two researchers independently examined the data for categories. In the fifth, or mapping and interpretation, stage, the categories were defined and then further refined. MAXQDA 2007 (VERBI GmbH, Berlin, Germany) software was used to analyze the data. 


\subsection{Trustworthiness}

To ensure trustworthiness, the criteria of Guba (1981) were used in the study (15). Credibility was established with regard to variation in participants' age, gender, occupation, and relationship to patients to provide a broad description of the phenomena. The principal researcher had a prolonged engagement with the study fields and used field notes to enhance data quality. Peer review was conducted by three experts with PhD degrees in nursing to verify the coding and categorization processes. The nursing experts were university teachers with sufficient experience in both teaching and conducting qualitative research. For member checking, six drafts of the interviews were returned to the participants to confirm that the researchers were presenting their actual perceptions. The participants were asked to read the drafts carefully and validate or refute the researchers' interpretation of data.

\subsection{Ethical Considerations}

The study was approved by the research ethics committee of the University of Social Welfare and Rehabilitation Sciences in Tehran, Iran, 2014 (Registration code: USWR.REC.1393.228). Appropriate permissions were obtained before entering the study fields. Participants were informed about the nature and aims of the research. They were also informed that taking part in the study was voluntary and that they had the right to quit the study at any time without being penalized. Consent for participation in the study and to tape record interviews were also obtained. The researcher assured the participants that their responses would be kept confidential and their identities would not be disclosed in the research reports. Each participant was identified by a chronologically assigned number.

\section{Results}

Seventeen family caregivers ( 9 female, 8 male) were interviewed. The participants were from 21 to 71 years of age, and their mean age was $44.88 \pm 12.05$ years. The subjects had different durations of caregiving experience, from one month to twelve years (Table 1 ).

Data analysis evidenced three main themes: 1) promoting functional recovery; 2) improving psychological health; and 3) strengthening social roles (Table 2).

Promoting positive recovery was determined to be the general theme. These three themes are explained separately with examples from the data. Participants are identified only by their assigned numbers.

\subsection{Theme 1: Promoting Functional Recovery}

The first theme that emerged from the data analysis is promoting functional recovery. It includes four subthemes: reviving and compensating the lost abilities, handling activities of daily living (ADL), dietary modifications, and monitoring the disease. All the family caregivers tried to help their patients recover these functions.

\subsubsection{Reviving and Compensating for Lost Physical Abilities}

The participants spoke of striving to help their patients regain their lost physical abilities by doing PT exercises or speech therapy. PT exercises were done in the clinics or in private homes. Many of the family caregivers performed passive exercises for the patients or encouraged them to do active exercises on a regular basis.

Examples of interview responses by participants are as follows:

Participant (P) 3: "I've done speech therapy for her, and I also help her to come to the PT clinic every afternoon and assist her to do exercise every evening at home." [Woman, aged 30 years]

P. 8: "PT is very important, those exercises and body activity. Those that make her move and she (the patient) mobilizes her body are helpful too." [Man, aged 49 years]

P. 11: "She performed PT exercises at the clinic, and my father bought PT equipment for her to do the activities at home." [Woman, aged 33 years]

P. 8: "I always tell my mother to do exercise. If you don't do exercise, you'll be worse.” [Man, aged 49 years]

\subsubsection{Handling Activities of Daily Living}

All the participants tried to compensate for their patients' physical disability through direct assistance in conducting personal ADL or by using moving aids such as a wheelchair, walker or cane. Some of the participants pointed out that they had modified their homes to increase their patients' ability to move about more easily.

P.1: "He couldn't move his legs and hands, and I helped him to go to the toilet and used diaper for him." [Woman, aged 61 years]

P. 12: “She wasn't able to do her personal tasks. I put food into her mouth and helped her to go the toilet and take a bath." [Woman, aged 43 years]

P. 2: "She can walk but by using a walker, and I am watchful not to let her fall, though." [Man, aged 61 years]

P. 6: “We've improved the house condition; we've made a toilet and bathroom next to her room and a sloping ramp for her easy movement." [Man, aged 34 years] 


\begin{tabular}{|c|c|c|c|c|c|c|}
\hline No & Age & Gender & Marital Status & Occupation & Relationship to the Patient & Duration of Caregiving, Months \\
\hline 1 & 61 & Female & Married & Housewife & Spouse & 12 \\
\hline 2 & 61 & Male & Married & Shopkeeper & Spouse & 9 \\
\hline 3 & 48 & Female & Single & Employee & Daughter & 5 \\
\hline 4 & 43 & Male & Divorced & Worker & Son & 1 \\
\hline 5 & 30 & Female & Single & Student & Daughter & 144 (12 years) \\
\hline 6 & 34 & Mmale & Married & Unemployed & Son & 18 \\
\hline 7 & 42 & Male & Married & Employed & Son & 18 \\
\hline 8 & 49 & Male & Married & Employed & Son & 12 \\
\hline 9 & 47 & Female & Married & Housewife & Daughter-in-law & 12 \\
\hline 10 & 42 & Male & Married & Driver & Son & 96 (8 years) \\
\hline 11 & 33 & Female & Married & Housewife & Daughter & 96 (8 years) \\
\hline 12 & 43 & Female & Married & Housewife & Daughter-in-law & 60 (5 years) \\
\hline 13 & 71 & Male & Married & Retired & Spouse & 1 \\
\hline 14 & 44 & Female & Married & Employed & Daughter & 1 \\
\hline 15 & 49 & Female & Married & Housewife & Daughter-in-law & 1 \\
\hline 16 & 21 & Female & Single & Student & Granddaughter & 1 \\
\hline 17 & 45 & Male & Married & Employed & Son & 18 \\
\hline
\end{tabular}

Table 2. Results of Interview Content Analysis Including General Theme, Main Themes, and Subthemes with Their Frequency and Percentage

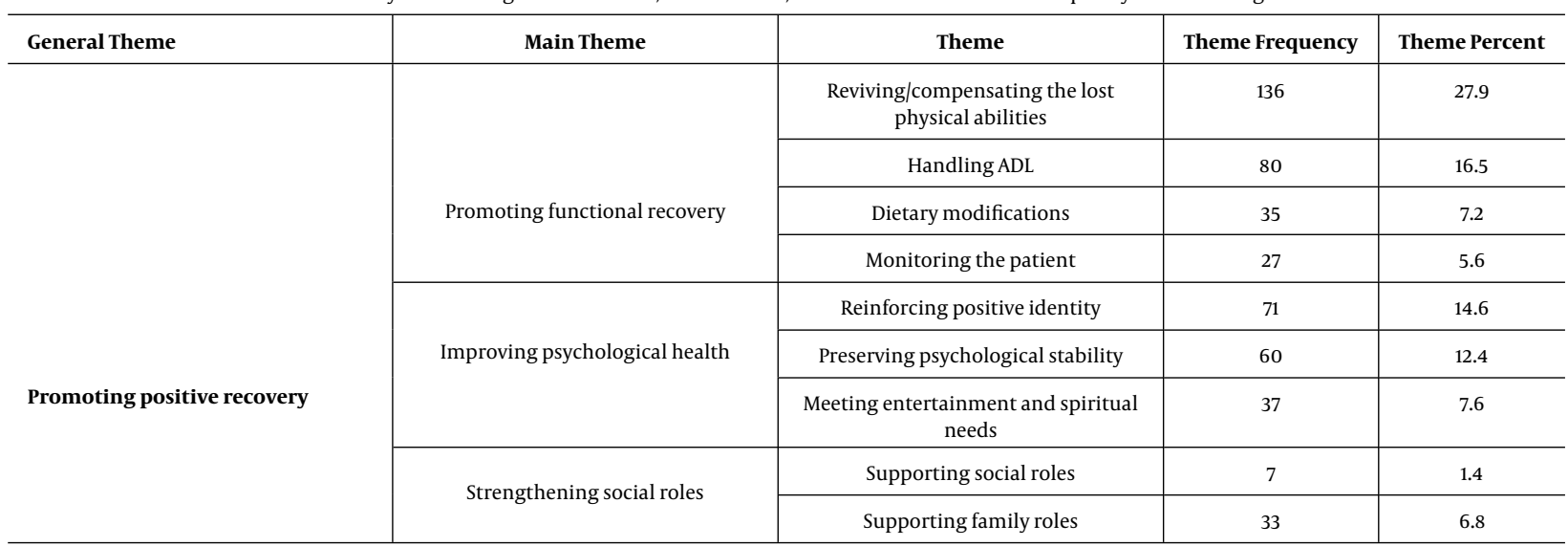

\subsubsection{Dietary Modifications}

Nearly all of the participants helped their patients eat and modified their daily dietary regime because of strokerelated dysphasia or other health-related problems such as hypertension and hyperlipidemia.

P. 14: "As she had difficulty in swallowing, I softened the food in the mixer and gave her meal with my hand." [Woman, aged 44 years]

P. 5: "His food should be different from others'. I don't add pepper and salt to his food. I also prepare boiled food instead of frying to him and taught him how to eat food."
[Woman, aged 30 years]

\subsubsection{Monitoring the Patient}

Many of the participants added that they monitored the health condition of their patients by checking blood pressure, blood sugar, skin condition, bowel problems, and ability to sleep. Some family caregivers performed routine checkups for the patients' comorbidities, such as heart and renal diseases.

P. 7: "I don't take her to health center very often. I check her blood pressure and sugar at home." [Man, aged 
42 years]

P. 10: "We take him to the doctor's office for medical checkups on time, for his heart and kidney or laboratory tests." [Man, aged 42 years]

P. 17: "I observed her for possible sign of bedsore and personal hygiene." [Man, aged 45 years]

\subsection{Theme 2: Improving Psychological Health}

The second theme that emerged from the study is improving psychological health. There are three subthemes: reinforcing positive identity, preserving psychological stability, and meeting entertainment and spiritual needs. Every family caregiver tried help the stroke patient recover psychologically.

\subsubsection{Reinforcing Positive Identity}

Nearly all the participants shared their experiences of how they strived to strengthen positive identity in their patients by listening to the patients and giving them the opportunity to make their own choices and to talk about the past when they wished.

P. 5: "My uncle is a lawyer, and he has my father's testament. He wrote, 'Do not use my assets as long as I am alive.” [Woman, aged 30 years]

P. 12: "She only accepts her own neurologist's advice and doesn't accept any other doctors, so we bring her to her doctor." [Woman, aged 43 years]

P. 3: "I always tell her that you brought us up and now this is our duty to look after you. If she wants me something I will provide it." [Woman, aged 48 years]

P.5: "I ask my father what you did when you were young. And dad told me about his naughtiness that no one knows, even my mother." [Woman, aged 30 years]

\subsubsection{Preserving Psychological Stability}

All the participants mentioned that they had maintained a calm psychological environment to the benefit of their patients and tried to protect them from any undue mental stress. They also tried to establish and maintain a caring relationship with their patients.

P. 10: We (patient's sons) are at his service anytime; we never allow him to get low spirits." [Man, aged 49 years]

P. 2: "I provided more calmness for her at home, calmness and peace of mind. These patients shouldn't have any annoyance ... I'm trying to give her this understanding that we're not tired of her and we love her." [Man, aged 61 years]

P. 10: "If a bad event happened to our family I remind anybody not to tell dad. I didn't want dad to get involved and feel upset." [Man, aged 42 years]

\subsubsection{Meeting Entertainment and Spiritual Needs}

Some of the family caregivers noted that their patients' preferred leisure activities at home to fill the time, and some actively tried to entertain them. Some participants attempted to meet the patients' spiritual needs.

P. 5: "He likes listening to radio very much, and after the stroke it became his major hobby." [Woman, aged 30 years]

P. 2: "I talked to her until evening or played a film on the $\mathrm{CD}$ player to entertain her. If she feels tired, I take her outside to patrol in the city." [Man, aged 61 years]

P. 16: "She loves listening to religious speech, and I play for her the audio tape that she like." [Woman, aged 21 years]

\subsection{Theme 3: Strengthening Social Roles}

The third theme in the present study is the strengthening of social roles, which consisted of two subthemes: supporting social roles and supporting family roles. Many participants thought that carrying out social roles, including internal familial roles, and the stroke patients' roles outside the family were so important for the patients, and they tried to support these roles.

\subsubsection{Supporting Social Roles}

P. 5: "Dad went outside by wheelchair; he went to his gardens and visited his properties." [Woman, aged 30 years]

P. 10: "We take him to an elderly day care center where he can meet his peers and other old women and men." [Man, aged 42 years]

P. 1: "My husband is sick; I've to go to the bank and shopping. He gave me the legal right to get his pension." [Woman, aged 61 years]

P. 5: "My brothers handle dad's farmland and bring the crops to him." [Woman, aged 30 years]

\subsubsection{Supporting Family Roles}

P. 12: "She spends time with her grandchildren and fills her free time." [Woman, aged 43 years]

P. 8: "We keep her grandchild with her, and her sister or brother comes to visit her." [Man, aged 49 years]

P. 10: "I take him to my home for dinner with family members. We sit together after dinner and talk about different matters. We try to accompany him and get his help and advice as before his illness." [Man, aged 42 years]

\subsection{Promoting Positive Recovery}

Promoting positive recovery is the general theme that emerged through data analysis. All participants developed their own ways to construct a positive recovery for their patients. 
P. 1: "I am really careful and give him good food. You should look after the patients very well. The doctor said mushroom is very useful for his recovery." [Woman, aged 61 years]

P.15: "These patients (with stroke) firstly must be under doctor's supervision. After coming home, you should take care of the patients very well to return them to health." [Woman, aged 49 years]

\section{Discussion}

Stroke recovery is a multifaceted phenomenon, including physical, psychological, and social domains which cannot be isolated from one another (16).

In agreement with the present study, Goldstein argued that one of the major goals of intervention during the poststroke recovery period was maximization of functional recovery (17). Therefore, much of the focus of stroke rehabilitation is on the recovery of impaired movement and the associated functions (18).

Physical and functional benefits of stroke patients' long-term participation in various types of physical activity are now well-established, and these benefits can result in improved recovery and function (19). Also, compatible with the present study, Jullamate and colleagues found that physical rehabilitation, which is one of the main categories related to informal rehabilitation, is provided by the stroke family caregiver to the patient (20). Galvin and others argued that family-mediated exercise therapy is an acceptable adjunct to routine physiotherapy after stroke (21).

Moreover, older stroke patients may require different ADL services than younger stroke patients (22). Congruent with the present study, one study showed that stroke patients are faced with a high degree of dependency on others, especially family members (12). It is also clear that the knowledge and skills of family caregivers related to the management of daily life is crucial for improvement in stroke patients (23).

Adequate hydration during the acute and subacute phases of stroke is crucial for reducing morbidity and mortality in this population (24). Malnutrition is common in the first few months after a stroke and contributes to a poor overall outcome (25). The identification and treatment of dysphagia and inadequate nutritional and feeding states in patients with stroke helps caregivers meet their rehabilitation goals for their patients (26), and the patient's family members have a major role in this aspect of the recovery. Poor family care can contribute to poor nutritional status and dehydration in stroke patients with dysphagia (27). Ensuring adequate hydration in acute stroke patients with dysphagia is a shared responsibility of the health-care team and family members (28).

The family caregiver is a vital factor in successful disease management (29). Pucciarelli et al. argue that family caregivers may not be adequately prepared to give suitable care to their stroke patients including monitoring of their symptoms (30). Many stroke family caregivers need more education about stroke signs, symptoms, complications, and the proper ways to manage these complications to prevent stroke recurrence $(31,32)$.

The dominant theme in the qualitative stroke literature is the effect of impairments on identity (33). Consistent with this research, Slade et al. in their systematic review conclude that one of the major components of the recovery process is identity, and, in particular, redefining and rebuilding a positive sense of identity are keys to the recovery process (34). Reconstruction of a positive selfidentity amid the disruption of chronic illness has been presented as occurring through two broad processes: the reconnection with valued aspects of the pre-illness self and the development of new, meaningful social identities (35), and the family has a major role to play in these processes. In fact, a family caregiver should proffer choices with which the stroke patient can identify (36). Compatible with the present research, the results of one study indicated that the availability of tangible support in stroke elders contributes to psychological well-being (37). Bergersen et al. showed, in their study, that most stroke patients $(88 \%)$ felt satisfied with the psychological support that they were provided by their family members (38). The support of family caregivers for their relatives with stroke has an important impact on whether patients can remain independent and outside institutional rehabilitation care (39). Tsouna-Hadjis et al. concluded that a high level of family support, including emotional care, is associated with progressive improvement of functional status, especially in severely impaired stroke patients, but the psychosocial status is also affected (40).

According to one study, stroke patients believed that recreation helps them sufficiently recover (41). Some passive leisure activities, including watching television, may increase after stroke (42). Secondary to aphasia, stroke patients engage in leisure activities that involve less speech and fewer conversations (43). Blomer et al. argue that the frequency of participation in vocational activities six months after the stroke decreased compared with before the stroke. This is significantly associated with participating restrictions experienced and satisfaction with participation (44). Family members may play a considerable role in removing obstacles to a stroke patient's participation in the vocational activities. Similar to the present study re- 
sults, it was shown that one-quarter to nearly one-half of stroke patients and family caregivers receive information about vacations, recreation, and entertainment (45).

Family caregivers need to be sensitive to the stroke patients' spiritual needs (46). Spiritual care is a fundamental component of a patient's care after stroke (47). Spiritual beliefs and practices are associated with improvement in all three outcome measures, including functional status, depression, and social activities of stroke patients after discharge (48).

Family members of stroke patients offer important social support which includes emotional encouragement and compliance with therapeutic instructions (40). Social support played a modest buffering role against declines in the performance of basic ADL among the most depressed elderly patients (49). Social support is associated with faster and more extensive recovery of functional status after stroke (50). Social interactions were shown to influence stroke outcome (51). According to Tsouna-Hadjis et al., patients with moderate to severe stroke and high-level family and social support attain a significantly better and progressively improved functional status than those with less support (40). Similar to the results of this research, Glymour et al. concluded that stroke patients in families with social ties and those with a higher degree of emotional support enjoy a better cognitive condition compared with socially isolated individuals or those with less emotional support (52).

Stroke is seen as a family matter in which the immediate family of the stroke patient tries to construct a positive recovery for their loved one (53). In agreement with the present research, Backstrom and Sundin showed that stroke patients' relatives experienced a growing sense of responsibility to construct a positive recovery (54). Burman also found that family caregivers constructed positive recovery as a primary strategy to attempt to promote their stroke patients' recovery (55).

The family has a significant role in the stroke patient's successful recovery. It is a process involving functional, psychological, and social elements. Health-care professionals can use the research findings to educate and prepare the stroke patients and their family members during hospitalization and after discharge from hospital to ensure better physical, psychological, and social recovery of the patients. The strong points of this study were its focus on the positive responses of family caregivers to the healthcare needs of stroke patients and the role ircmj\$27686 of family caregivers in the care of the patient after the discharge from the hospital.

\subsection{Limitations}

The study findings are based on the qualitative data analysis from only 17 family caregivers, so they cannot be generalized to the target population. This calls for cautious interpretation concerning the leading factors of stroke recovery.

\section{Acknowledgments}

The authors appreciate the stroke family caregivers whose experience helped the authors complete this article. The first author is also thankful to the PhD dissertation committee of the University of Social Welfare and Rehabilitation Sciences in Tehran, Iran, which guided this research.

\section{Footnotes}

Authors' Contribution: Study topic and design, Ali Hesamzadeh, Asghar Dalvandi, Sadat Bagher Maddah, Masoud Fallahi Khoshknab and Fazlollah Ahmadi; data collection, Ali Hesamzadeh; analysis and interpretation of data, Ali Hesamzadeh, Asghar Dalvandi, Sadat Bagher Maddah, Masoud Fallahi Khoshknab and Fazlollah Ahmadi; drafting of the manuscript, Ali Hesamzadeh; scientific revision of the manuscript, Ali Hesamzadeh, Asghar Dalvandi, Sadat Bagher Maddah, Masoud Fallahi Khoshknab and Fazlollah Ahmadi; research project administration, Ali Hesamzadeh, Asghar Dalvandi, Sadat Bagher Maddah, Masoud Fallahi Khoshknab and Fazlollah Ahmadi.

Funding/Support: This article is an extract from sections of a PhD thesis. The research project was approved and supported by the University of Social Welfare and Rehabilitation Sciences, Tehran, Iran, (Grant number: 92/801/A/2/7245).

\section{References}

1. Mackay J, Mensah GA. The atlas of heart disease and stroke. Geneva: World Health Organization; 2004.

2. Azarpazhooh MR, Etemadi MM, Donnan GA, Mokhber N, Majdi MR, Ghayour-Mobarhan M, et al. Excessive incidence of stroke in Iran: evidence from the Mashhad Stroke Incidence Study(MSIS), a populationbased study of stroke in the Middle East. Stroke. 2010;41(1):3-10. doi: 10.1161/STROKEAHA.109.559708. [PubMed: 19926844].

3. Cowman S, Royston M, Hickey A, Horgan F, McGee H, O'Neill D. Stroke and nursing home care: a national survey of nursing homes. BMC Geriatr. 2010;10:4. doi: 10.1186/1471-2318-10-4. [PubMed: 20105313].

4. Kalra L, Langhorne P. Facilitating recovery: evidence for organized stroke care. J Rehabil Med. 2007;39(2):97-102. doi: 10.2340/165019770043. [PubMed: 17351689].

5. Fukui S, Shimizu Y, Rapp CA. A Cross-cultural study of recovery for people with psychiatric disabilities between U.S. and Japan. Community Ment Health J. 2012;48(6):804-12. doi: 10.1007/s10597-012-9513-2. [PubMed: 22569787]. 
6. Xie H. Recovery in Mental Illnesses: a Concept Analysis. Int J Caring Sci. 2013;6(3):439.

7. Strudwick A, Morris R. A qualitative study exploring the experiences of African-Caribbean informal stroke carers in the UK. Clin Rehabil. 2010;24(2):159-67. doi: 10.1177/0269215509343847. [PubMed: 20103577].

8. Santos S, Maria B, Lima A, Irani I. Caregivers' conception of the care provided to the elderly.J Nurs UFPE. 2014;8(9):3069-75.

9. McCabe PJ, Saban KL, Cohn J, Crane P, Biddle M, Beckie TM. Report from the Council on Cardiovascular and Stroke Nursing. J Cardiovasc Nurs. 2015;30(2):92-5. doi: 10.1097/JCN.0000000000000200. [PubMed: 25664532].

10. Dowswell G, Lawler J, Dowswell T, Young J, Forster A, Hearn J. Investigating recovery from stroke: a qualitative study. J Clin Nurs. 2000;9(4):507-15. [PubMed: 11261130].

11. Armstrong NP, Steffen JJ. The recovery promotion fidelity scale: assessing the organizational promotion of recovery. Community Ment Health J. 2009;45(3):163-70. doi: 10.1007/s10597-008-9176-1. [PubMed: 19082712].

12. Dalvandi A, Heikkila K, Maddah SS, Khankeh HR, Ekman SL. Life experiences after stroke among Iranian stroke survivors. Int Nurs Rev. 2010;57(2):247-53. doi: 10.1111/j.1466-7657.2009.00786.x. [PubMed: 20579161].

13. Elo S, Kyngas $\mathrm{H}$. The qualitative content analysis process. J Adv Nurs. 2008;62(1):107-15. doi: 10.1111/j.1365-2648.2007.04569.x. [PubMed: 18352969].

14. Bryman A, Burgess RG. Analyzing qualitative data. New York: Taylor \& Francis e-Library; 2002.

15. Guba EG. Criteria for assessing the trustworthiness of naturalistic inquiries. ECTJ. 1981;29(2):75-91.

16. Vanhook P. The domains of stroke recovery: a synopsis of the literature. J Neurosci Nurs. 2009;41(1):6-17. [PubMed: 19368067].

17. Goldstein LB. Rehabilitation and Recovery After Stroke. Curr Treat Options Neurol. 2000;2(4):319-28. [PubMed: 11096757].

18. Langhorne P, Coupar F, Pollock A. Motor recovery after stroke: a systematic review. Lancet Neurol. 2009;8(8):741-54. doi: 10.1016/S14744422(09)70150-4. [PubMed: 19608100].

19. Morris JH, Williams B. Optimising long-term participation in physical activities after stroke: exploring new ways of working for physiotherapists. Physiotherapy. 2009;95(3):228-34. doi: 10.1016/j.physio.2008.11.006. [PubMed: 19635344].

20. Jullamate P, de Azeredo Z, Paul C, Subgranon R. Thai stroke patient caregivers: who they are and what they need. Cerebrovasc Dis. 2006;21(1-2):128-33. doi: 10.1159/000090211. [PubMed: 16340188].

21. Galvin R, Cusack T, Stokes E. Physiotherapy after stroke in Ireland: a qualitative insight into the patients' and physiotherapists' experience. Int J Rehabil Res. 2009;32(3):238-44. doi: 10.1097/MRR.0b013e32832b083c. [PubMed: 19381097].

22. Walker TD. The effectiveness of perceived social support and adherence on activities of daily living performance ( $A D L)$ and functional outcomes in first time stroke survivors [Dissertation]. Ann Arbor: Southern University and Agricultural and Mechanical College; 2012.

23. Dalvandi A, Ekman SL, Khankeh HR, Maddah SS, Heikkila K. Rehabilitation experts' experience of community rehabilitation services for stroke survivors in Iran. Top Stroke Rehabil. 2012;19(5):395-404. doi: 10.1310/tsr1905-395. [PubMed: 22982826].

24. McGrail A, Kelchner L. Barriers to oral fluid intake: beyond thickened liquids. J Neurosci Nurs. 2015;47(1):58-63. doi: 10.1097/JNN.0000000000000114. [PubMed: 25565596].

25. Paquereau J, Allart $\mathrm{E}$, Romon $\mathrm{M}$, Rousseaux $\mathrm{M}$. The longterm nutritional status in stroke patients and its predictive factors. J Stroke Cerebrovasc Dis. 2014;23(6):1628-33. doi: 10.1016/j.jstrokecerebrovasdis.2014.01.007. [PubMed: 24680090].

26. Finestone HM, Greene-Finestone LS. Rehabilitation medicine: 2. Di- agnosis of dysphagia and its nutritional management for stroke patients. CMAJ. 2003;169(10):1041-4. [PubMed: 14609974].

27. Bouziana SD, Tziomalos K. Malnutrition in patients with acute stroke. J Nutr Metab. 2011;2011:167898. doi: 10.1155/2011/167898. [PubMed: 22254136].

28. Whelan K. Inadequate fluid intakes in dysphagic acute stroke. Clin Nutr. 2001;20(5):423-8. doi: 10.1054/clnu.2001.0467. [PubMed: 11534937].

29. Wilkinson AM, Lynn J. Caregiving for advanced chronic illness patients. Tech Reg Anesth Pain Manag. 2005;9(3):122-32.

30. Pucciarelli G, Savini S, Byun E, Simeone S, Barbaranelli C, Vela RJ, et al. Psychometric properties of the Caregiver Preparedness Scale in caregivers of stroke survivors. Heart Lung. 2014;43(6):555-60. doi: 10.1016/j.hrtlng.2014.08.004. [PubMed: 25239706].

31. Hafsteinsdottir TB, Vergunst M, Lindeman E, Schuurmans M. Educational needs of patients with a stroke and their caregivers: a systematic review of the literature. Patient Educ Couns. 2011;85(1):14-25. doi: 10.1016/j.pec.2010.07.046. [PubMed: 20869189].

32. Bakas T, Austin JK, Okonkwo KF, Lewis RR, Chadwick L. Needs, concerns, strategies, and advice of stroke caregivers the first 6 months after discharge. J Neurosci Nurs. 2002;34(5):242-51. [PubMed: 12391740].

33. Anderson S, Whitfield K. Social identity and stroke: 'they don't make me feel like, there's something wrong with me'. Scand J Caring Sci. 2013;27(4):820-30. doi: 10.1111/j.1471-6712.2012.01086.x. [PubMed: 23121474].

34. Slade M, Leamy M, Bacon F, Janosik M, Le Boutillier C, Williams $\mathrm{J}$, et al. International differences in understanding recovery: systematic review. Epidemiol Psychiatr Sci. 2012;21(4):353-64. doi: 10.1017/S2045796012000133. [PubMed: 22794507].

35. Reynolds $F$. Reclaiming a positive identity in chronic illness through artistic occupation. OTJR. 2003;23(3):118-27.

36. Proot IM, Crebolder HF, Abu-Saad HH, Ter Meulen RH. Autonomy in the rehabilitation of stroke patients in nursing homes. A concept analysis. Scand J Caring Sci. 1998;12(3):139-45. [PubMed: 9801636].

37. Hilton EL. The meaning of stroke in elderly women: The lived experience [Dissertation]. Ann Arbor: The University of Alabama at Birmingham; 1999.

38. Bergersen H, Froslie KF, Stibrant Sunnerhagen K, Schanke AK. Anxiety, depression, and psychological well-being 2 to 5 years poststroke. J Stroke Cerebrovasc Dis. 2010;19(5):364-9. doi: 10.1016/j.jstrokecerebrovasdis.2009.06.005. [PubMed: 20547073].

39. Han B, Haley WE. Family caregiving for patients with stroke. Review and analysis. Stroke. 1999;30(7):1478-85. [PubMed: 10390326].

40. Tsouna-Hadjis E, Vemmos KN, Zakopoulos N, Stamatelopoulos S. Firststroke recovery process: the role of family social support. Arch Phys Med Rehabil. 2000;81(7):881-7. doi: 10.1053/apmr.2000.4435. [PubMed: 10895999].

41. Cowdell F, Garrett D. Recreation in stroke rehabilitation part two: exploring patients' views. IJTR. 2003;10(10).

42. Drummond A. Leisure activity after stroke. Int Disabil Stud. 1990;12(4):157-60. [PubMed: 2103567].

43. Moshref RJ. Factors influencing leisure participation post stroke including physical, psychological, and social deficits [Thesis]. Ann Arbor: Touro College; 2003.

44. Blomer AM, van Mierlo ML, Visser-Meily JM, van Heugten CM, Post MW. Does the frequency of participation change after stroke and is this change associated with the subjective experience of participation? Arch Phys Med Rehabil. 2015;96(3):456-63. doi: 10.1016/j.apmr.2014.09.003. [PubMed: 25264108].

45. Wachters-Kaufmann C, Schuling J, The H, Meyboom-de Jong B. Actual and desired information provision after a stroke. Patient Educ Couns. 2005;56(2):211-7. doi: 10.1016/j.pec.2004.02.012. [PubMed: 15653251].

46. King RB, Semik PE. Stroke caregiving: difficult times, resource use, and needs during the first 2 years. J Gerontol Nurs. 2006;32(4):37-44. 
[PubMed: 16615711].

47. Creutzfeldt CJ, Holloway RG, Walker M. Symptomatic and palliative care for stroke survivors. J Gen Intern Med. 2012;27(7):853-60. doi: 10.1007/s11606-011-1966-4. [PubMed: 22258916].

48. Popovich JM. Hope, coping and rehabilitation outcomes in stroke patients [Dissertation]. Ann Arbor: Rush University; 1991.

49. Hays JC, Steffens DC, Flint EP, Bosworth HB, George LK. Does social support buffer functional decline in elderly patients with unipolar depression? Am J Psychiatry. 2001;158(11):1850-5. doi: 10.1176/appi.ajp.158.11.1850. [PubMed: 11691691].

50. Glass TA, Matchar DB, Belyea M, Feussner JR. Impact of social support on outcome in first stroke. Stroke. 1993;24(1):64-70. [PubMed: 8418553].

51. Silasi G, Hamilton DA, Kolb B. Social instability blocks functional restitution following motor cortex stroke in rats. Behav Brain Res. 2008;188(1):219-26. doi: 10.1016/j.bbr.2007.10.030. [PubMed:
18068823].

52. Glymour MM, Weuve J, Fay ME, Glass T, Berkman LF. Social ties and cognitive recovery after stroke: does social integration promote cognitive resilience? Neuroepidemiology. 2008;31(1):10-20. doi: 10.1159/000136646. [PubMed: 18535395].

53. Backstrom B, Sundin K. The experience of being a middle-aged close relative of a person who has suffered a stroke, 1 year after discharge from a rehabilitation clinic: a qualitative study. Int J Nurs Stud. 2009;46(11):1475-84. doi: 10.1016/j.ijnurstu.2009.04.009. [PubMed: 19477447].

54. Backstrom B, Sundin K. The experience of being a middle-aged close relative of a person who has suffered a stroke-six months after discharge from a rehabilitation clinic. Scand J Caring Sci. 2010;24(1):11624. doi: 10.1111/j.1471-6712.2009.00694.x. [PubMed: 19497028].

55. Burman ME. Family caregiver expectations and management of the stroke trajectory. Rehabil Nurs. 2001;26(3):94-9. [PubMed: 12035695]. 